\title{
Desenvolvimento de uma fruteira para supermercados com base nos princípios ergonômicos e do Design Universal
}

\author{
Development of a Supermarket Fruit Bowl Based on Ergonomic Principles and \\ Universal Design
}

OLIVEIRA, Thays Costa; Graduanda; UFAL

thaysdacosta@gmail.com

ROSA, Maria Eduarda Ramos Cavalcanti; Mestre; UFAL

dudah.cavalcanti@gmail.com

\section{Resumo}

O artigo apresenta um resumo do processo de desenvolvimento de uma fruteira para supermercados com abordagem na ergonomia e no design universal. É mostrada a fundamentação teórica do design acessível, design universal e ergonomia com a intenção de buscar soluções para o produto. Serão explorados assuntos como: a percepção humana em diferentes níveis e questões ergonômicas, a fim de estabelecer requisitos para o desenvolvimento de uma fruteira de supermercado inclusiva. A metodologia modelada possibilitou uma solução mais coerente aos sistemas de informação para a adequação do produto ao maior número de usuários. Incluem-se nesse público, pessoas com restrição visual, mobilidade reduzida e quaisquer outras formas de deficiência física.

Palavras Chave: design de produto, fruteiras, design universal.

\begin{abstract}
The article presents a summary of the development process of a fruit bowl for supermarkets with a focus on ergonomics and universal design. The theoretical basis of accessible design, universal design and ergonomics with the intention of seeking solutions for the product is shown. Subjects such as: human perception at different levels and ergonomic issues will be explored in order to establish requirements for the development of an inclusive supermarket fruit tree. The modeling methodology allowed a more coherent solution to the information systems for the suitability of the product to the greater number of users. This includes persons with visual impairment, reduced mobility and any other forms of physical disability.
\end{abstract}

Keywords: product design, fruit trees, universal design. 


\section{Introdução}

A sociedade contemporânea é caracterizada pela aceleração do tempo e diversidade, onde segundo Norbert Elias (1990), o homem tem sua relação com o tempo através das implicações que o meio ambiente traz, ou seja, com os processos físicos e sociais estabelecidos. Sendo assim, algumas tarefas corriqueiras, como a de ir ao supermercado, por exemplo, se tornaram muito complexas em decorrência do estilo de vida adotado pelo homem e do pouco tempo para executá-las.

De Acordo com Kotler e Keller (2006), diversos aspectos influenciam o comportamento do consumidor, entre eles, os fatores culturais, sociais, pessoais e psicológicos. Entender como esses consumidores se relacionam com os produtos, serviços, marcas, e principalmente, como fazem suas escolhas, são primordiais para a elaboração de estratégias de marketing e desenvolvimento de produtos e projetos diversos.

Procurar tornar mais prazerosa e acessível às atividades rotineiras dos indivíduos, torna-se pertinente aos estabelecimentos contemporâneos. Isso se deve ao fato de que, segundo dados do Instituto Brasileiro de Geografia e Estatística (IBGE, 2010), 23,9\% da população brasileira têm algum tipo de deficiência (auditiva, visual, física e intelectual), além do envelhecimento populacional, que representa um contingente de quase 15 milhões ( $8,6 \%$ da população brasileira) (IBGE, 2002).

Alguns grupos sociais acabam sendo forçados a modificar sua rotina e hábitos de vida pelo seu desempenho físico e habilidades motoras reduzidas, em decorrência da dificuldade em realizar atividades, levando-os ao isolamento social pela falta de autonomia. Nesse sentido, a garantia dos princípios de inclusão envolvem iniciativas nos diferentes segmentos sociais, como a facilitação do acesso, a utilização de objetos e ferramentas e a remoção de barreiras físicas.

De acordo com Lima e Silva (2007), tais iniciativas buscam eliminar ou ao menos minimizar o preconceito, estigma e estereótipos que resultam em discriminação contra pessoas com deficiência. São atitudes que influenciam diretamente no desenvolvimento e dificultam a permanência dessas pessoas em diversos âmbitos sociais.

No âmbito dos supermercados e hortifrútis é importante compreender que para a comercialização das frutas é necessária à apreciação positiva do consumidor, e está relacionada principalmente com a aparência e com as características sensoriais, além da garantia de segurança e qualidade, possibilitando o estabelecimento de estratégias diferenciadas de comercialização (GUTIERREZ, 2005).

Para que essas frutas cheguem às nossas casas, elas passam pelo processo de seleção, empacotamento e transporte, que podem comprometer na sua qualidade. Para tanto, as embalagens são bastante importantes. Entretanto, nem todas as frutas são embaladas antes de chegarem ao consumidor. Muitas delas precisam ser escolhidas considerando seu aspecto visual, bem como, o tato e o olfato.

Dessa maneira, a tarefa de escolher as frutas nos supermercados e feiras pode ser otimizada com o auxílio da setorização dos produtos em fruteiras, de acordo com as características climáticas que cada tipo demanda. 
Figura 1 - Processo de distribuição das frutas

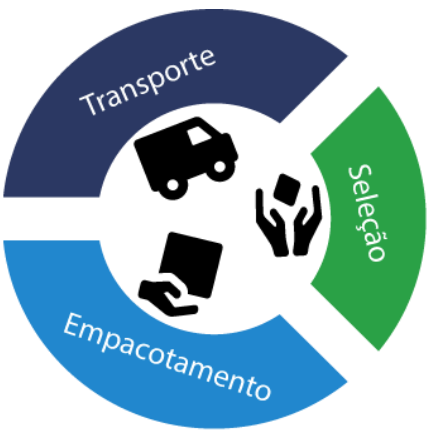

Fonte: o autor

Para que isso ocorra da melhor maneira possível, há necessidade de aquisição de mobiliários e objetos que proporcionem a disposição dos produtos, de modo a facilitar o processo de escolha pelo consumidor. A pertinência de se identificar as dificuldades de diferentes pessoas, durante a realização dessas tarefas, é imprescindível para avaliar se esses mobiliários e objetos são acessíveis às particularidades dos consumidores.

Desse modo, o presente artigo visa realizar um estudo de caso em alguns supermercados da cidade de Maceió, Alagoas, com o ideal de verificar a acessibilidade das fruteiras dos supermercados dessa localidade aos seus usuários.

\section{Revisão bibliográfica}

O Design Universal pode ser compreendido como um processo de idealização de produtos concebidos às necessidades da maioria das pessoas, melhorando a sua usabilidade e permitindo a acessibilidade. São incluídos todos os gêneros, raças, idades, classes sociais, tamanhos, bem como, pessoas com deficiências e limitações (BIFANO, 2000). Trata-se da maneira de arquitetar produtos, que deve ser feita em associação com os sete princípios básicos estabelecidos pelo CUD (2002):

Quadro 1 - Princípios do Design Universal.

\begin{tabular}{|c|c|}
\hline Princípios & Referência \\
\hline Uso equitativo & $\begin{array}{l}\text { O design útil, comercializável, atraente e seguro para pessoas com diferentes } \\
\text { habilidades sem estigmatizar ou segregar qualquer usuário. }\end{array}$ \\
\hline Flexibilidade de uso & $\begin{array}{l}\text { Englobar uma extensa variedade de preferências e habilidades pessoais, permitindo } \\
\text { escolha do método de utilização, adaptabilidade ao ritmo e precisão do usuário. }\end{array}$ \\
\hline Uso intuitivo & $\begin{array}{l}\text { A compreensão do design deve ser independente da experiência do usuário, } \\
\text { conhecimento, competência linguística ou concentração. Eliminar as complexidades de } \\
\text { uso, corresponder às expectativas e intuição do usuário e hierarquizar informações. }\end{array}$ \\
\hline Informação perceptível & $\begin{array}{l}\text { Comunicar e informar, independentemente da habilidade do usuário ou ambiente em } \\
\text { que se encontra. Diferenciar e contrastar elementos, utilizar diferentes meios de } \\
\text { apresentação e permitir o acesso a estas informações às pessoas com limitações }\end{array}$ \\
\hline
\end{tabular}


Tolerância ao erro

Baixo esforço físico

Tamanho do espaço

Para acesso e uso sensoriais.

Atenuar os riscos e consequências adversas de acidentes. Deve fornecer avisos de perigo, manter isolado elementos perigosos e prevenir ações inconscientes em tarefas que requerem atenção.

Design confortável com o mínimo de fadiga. Precisa permitir que o usuário mantenha uma posição neutral do corpo e realizar esforços de trabalho razoáveis para a tarefa, eliminando ações repetitivas e esforço físico excessivo.

O espaço para aproximação, uso e alcance deve ser apropriado independentemente do tamanho do corpo do usuário, postura ou mobilidade. Deve fornecer uma visão clara de elementos importantes e acesso a todos os elementos, independentemente do usuário estar sentado ou em pé.

Fonte: adaptado de CUD (2017)

Com base nesses princípios, o design universal atua de forma determinante na concepção de espaços, artefatos e objetos visando atender simultaneamente a todas as pessoas, com diferentes características antropométricas e sensoriais, de forma independente, segura e confortável. Para a realização de um produto coerente com a realidade e necessidades específicas dos usuários, é importante utilizar da ergonomia física e cognitiva em conjunto.

Segundo IIDA (2005), a ergonomia física trata da relação das características anatômicas, antropométricas, fisiológicas e biomecânicas do homem com a atividade física realizada. Enquanto que a ergonomia cognitiva compreende processos mentais nas interações do homem com os elementos de um sistema e/ou produto.

Os estudos ergonômicos contribuem na solução de problemas de usabilidade, tornando os produtos mais adequados à saúde, segurança, conforto e eficiência e minimizando os erros (ADUL et al., 2004). Porém, não se consegue fazer a dissociação de um produto do ambiente onde ele está inserido. Nesse tocante, a ergonomia ocupa-se não só da relação do homem com o objeto, mas também do homem com o ambiente onde está inserido, sendo A Ergonomia do Ambiente Construído - EAC, um segmento que amplia o olhar para o ambiente, os objetos e considera, além do usuário, a tarefa realizada.

Quando a qualidade da usabilidade não se dá de maneira adequada, podem ser corrigidas, admitindo o benefício no contexto futuro de uso. Para tais modificações, são observadas determinadas circunstâncias que comprometem a qualidade da tarefa ou mesmo a inviabilidade da sua realização. Como consequência, pretendem-se minimizar constrangimento, má compreensão, traumas, dentre outros fatores, na relação usuário-produto ou usuário-sistema interativo (CYBIS et al., 2010)

\section{Metodologia}

Neste projeto foi utilizada a metodologia de Lobach (2001) com algumas ferramentas propostas por Baxter (2015) e pelo Design Thinking (2008). Lobach (2001) divide o processo de 
design em quatro fases distintas, e explana que embora divididas, estas fases nunca são separáveis, podendo haver avanços e retrocessos no processo. Tais fases projetuais são: I) fase de preparação, ou seja, Análise do Problema; II) fase da geração, que indica a Definição do Problema e dos objetos; III) Geração de Alternativas de design; IV) Avaliação das Alternativas e V) Solução e Realização.

Assim, integrando a ergonomia e acessibilidade, o foco da aplicação prática em questão consiste em apresentar as fases metodológicas utilizadas para a geração de um novo produto, que proporcione uma experiência inclusiva e prática, bem como atender a uma demanda de um produto que ofereça maior praticidade e segurança durante a sua manipulação.

$\mathrm{Na}$ fase de análise do problema, as ferramentas utilizadas foram a Pesquisa Desk, do Design Thinking (2008) e o Mapa Mental, proposto por Buzan (2005). A Pesquisa Desk trata-se de uma imersão no universo do produto, sendo importante para que o projetista desenvolva uma análise crítica a respeito dos produtos existentes de um determinado nicho de mercado. Em seguida, a ferramenta utilizada foi o Mapa Mental, que consiste em uma ferramenta que permite o mapeamento dos principais problemas do produto em questão.

A etapa seguinte foi a Análise de Usuário, ferramenta proposta por Loach (2001), com o intuito de coletar informações sobre os usuários e suas dificuldades em utilizar as fruteiras já existentes no mercado. Assim, foi elaborado um questionário contendo perguntas pertinentes à pesquisa, com respostas de 20 usuários. Outra análise realizada pela proposição do referido autor foi à morfológica e estrutural. O objetivo da estrutural é de tornar transparente a estruturação das fruteiras similares, mostrando sua complexidade e na morfológica é compreender a forma da fruteira e como isso interfere na sua função.

A Análise de Similares trata-se da análise dos concorrentes (BAXTER, 1998), que serve para comparar entre si os produtos similares existentes no mercado. Nessa pesquisa foi possível avaliar os aspectos qualitativos e quantitativos que podem ser relevantes para o desenvolvimento do novo produto. Nesta fase, todos os dados foram levantados e analisados em paralelo às pesquisas bibliográficas, para que fosse possível realizar uma análise do mercado atual de produtos do segmento em questão.

Para a análise ergonômica foram estudados dados antropométricos e realizou-se a Análise da Tarefa, que se trata de uma das etapas da Análise Ergonômica do Trabalho (AET), proposta por Vidal (2008) e Wisner (1987). Nesta fase, é analisado como o usuário deve se comportar durante a execução das atividades, assim como os procedimentos, equipamentos, ambiente e condicionantes temporais que influenciam diretamente ou indiretamente no exercício da mesma.

Por fim, a análise morfológica consiste em conhecer a estrutura da forma do produto similar, partindo da ideia da figura geométrica básica, até a compreensão da coerência formal.

\section{Resultados e Discussão}

\subsection{Análises da fruteira}

Através do Mapa mental (figura 2), foi possível identificar que a causa dos problemas está relacionada à ausência de mobiliários que proporcionem acesso a diferentes usuários. Outro ponto percebido foi que a temática projetual abordada não é muito explorada pelos designers e 
profissionais da área de projeto, apesar de se tratar de um assunto muito importante, a inclusão.

Figura 2 - Mapa Mental

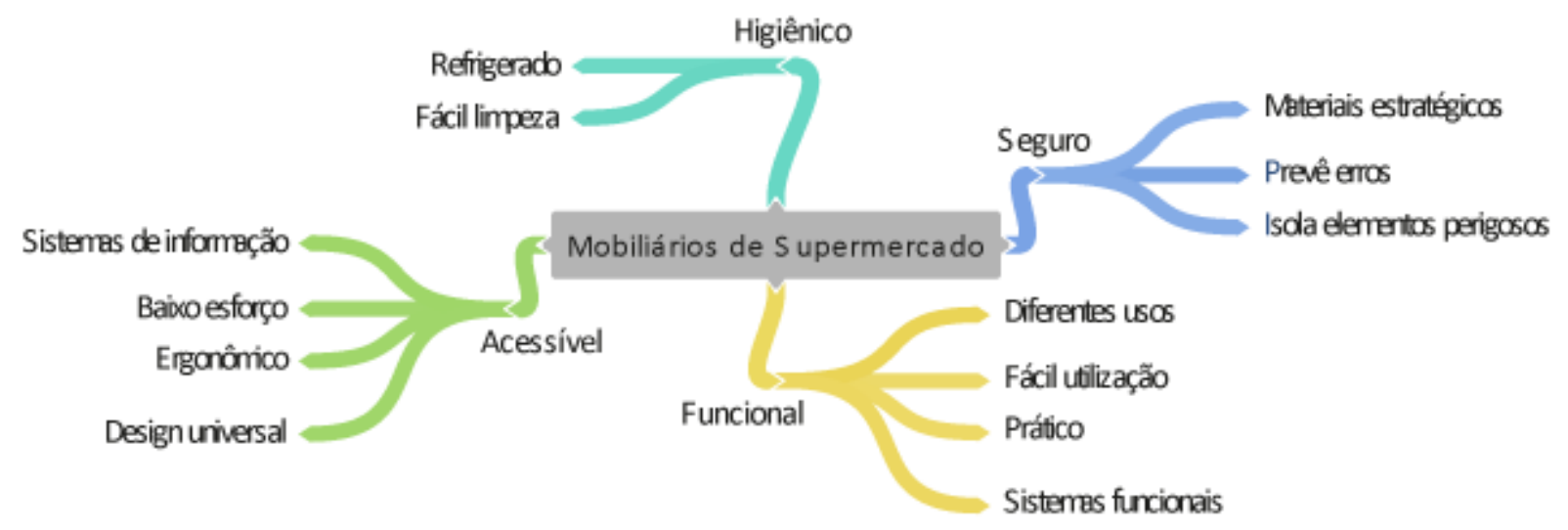

Fonte: o autor

O questionário aplicado se estendeu às pessoas que frequentam os supermercados da cidade de Maceió, Alagoas e a Associação de Deficientes Físicos de Alagoas (ADEFAL), tendo como objetivo colher dados de pessoas que fazem parte do público alvo do estudo. O questionário coletou informações sobre a idade dos usuários, tipos de deficiência e/ou dificuldades, além das preferências (cores, formas, materiais) dos entrevistados. O resultado, a seguir:

- Pessoas sem necessidades especiais: A maioria dos usuários pertencentes a esse grupo não vê dificuldade na utilização dos produtos existentes, porém, acham que os mesmos não conservam bem as frutas, além de não serem higiênicos. Com relação às preferências de forma e cor, os usuários se dividem ao escolher entre formas curvas e retangulares, e ainda, uma grande maioria prefere as cores saturadas.

- Pessoas com necessidades especiais: Os usuários que responderam ao questionário possuem deficiências como: Paraplegia, AVC e deficiência visual. Com relação ao uso do produto, grande parte tem dificuldade na utilização e deve-se ao fato das fruteiras estarem em lugares altos, apertados e/ou distantes. Acham que as fruteiras existentes não conservam bem as frutas e se dividem com relação à preferência entre formas curvas/retangulares e cores saturadas e sóbrias.

$\mathrm{Na}$ Análise de similares, percebeu que os produtos que exigem menos força e dispõem a mesma fruta, em diferentes alturas, são os preferíveis como parâmetros projetuais, uma vez que os mesmos apresentam preocupação ergonômica com o usuário e facilitam a utilização. 
Figura 3 - Fruteiras Concorrentes

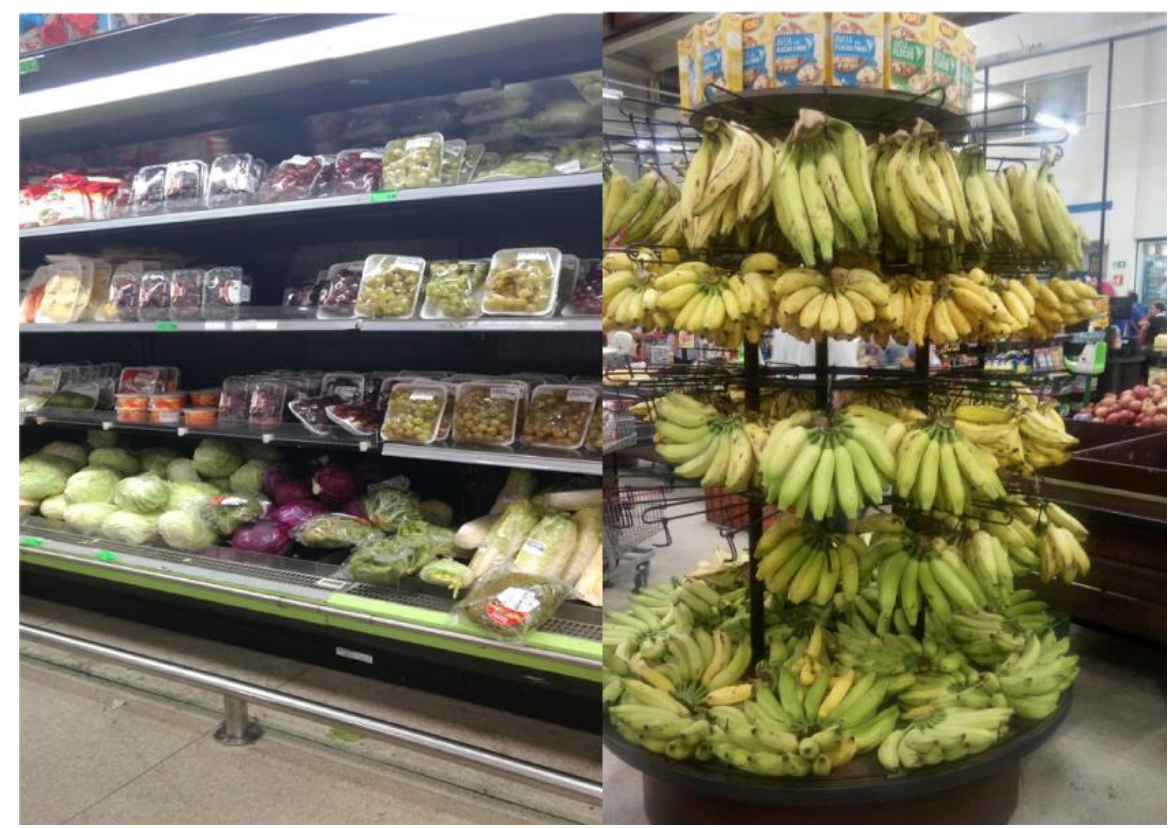

Fonte: o autor

A partir do estudo estrutural e morfológico dos similares, foi possível reconhecer e compreender os tipos de componentes, a importância dos mesmos e as relações entre eles. Nas figuras 4 e 5 são apresentados os resultados.

\section{Figura 4-Análise Estrutural}

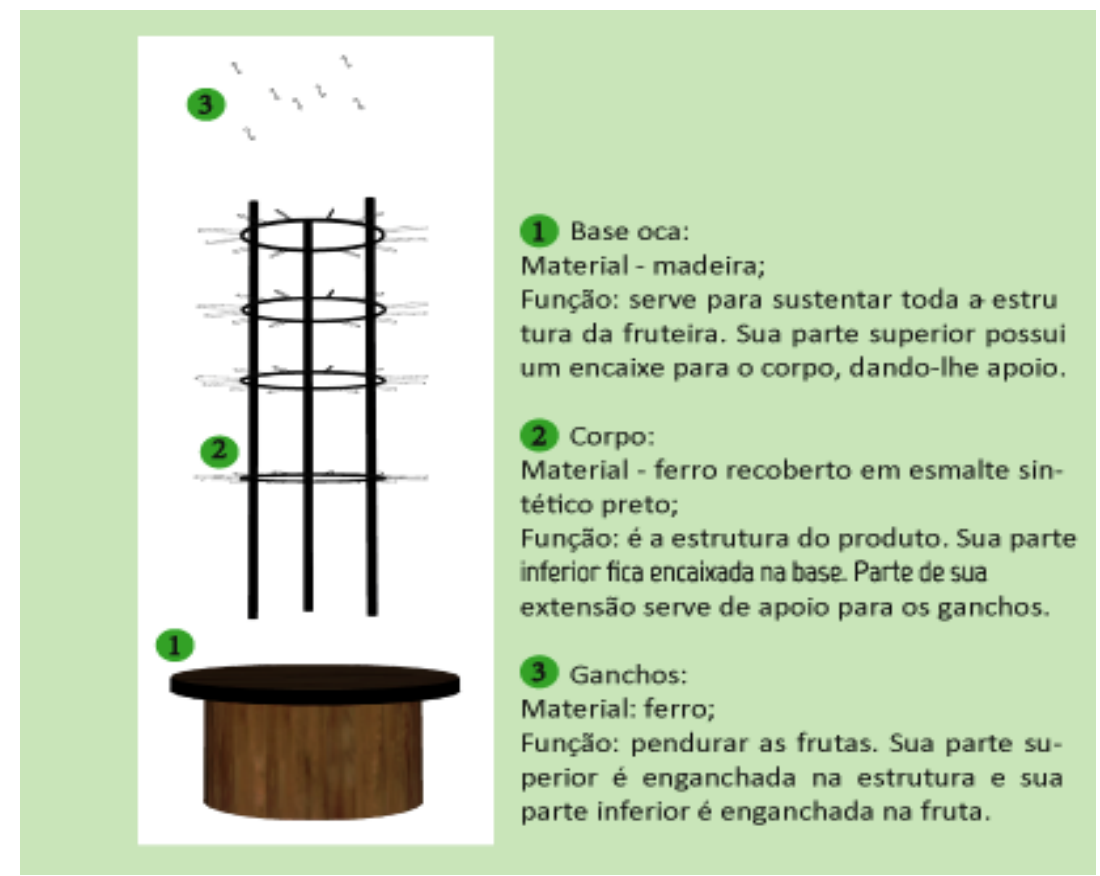

Fonte: o autor 


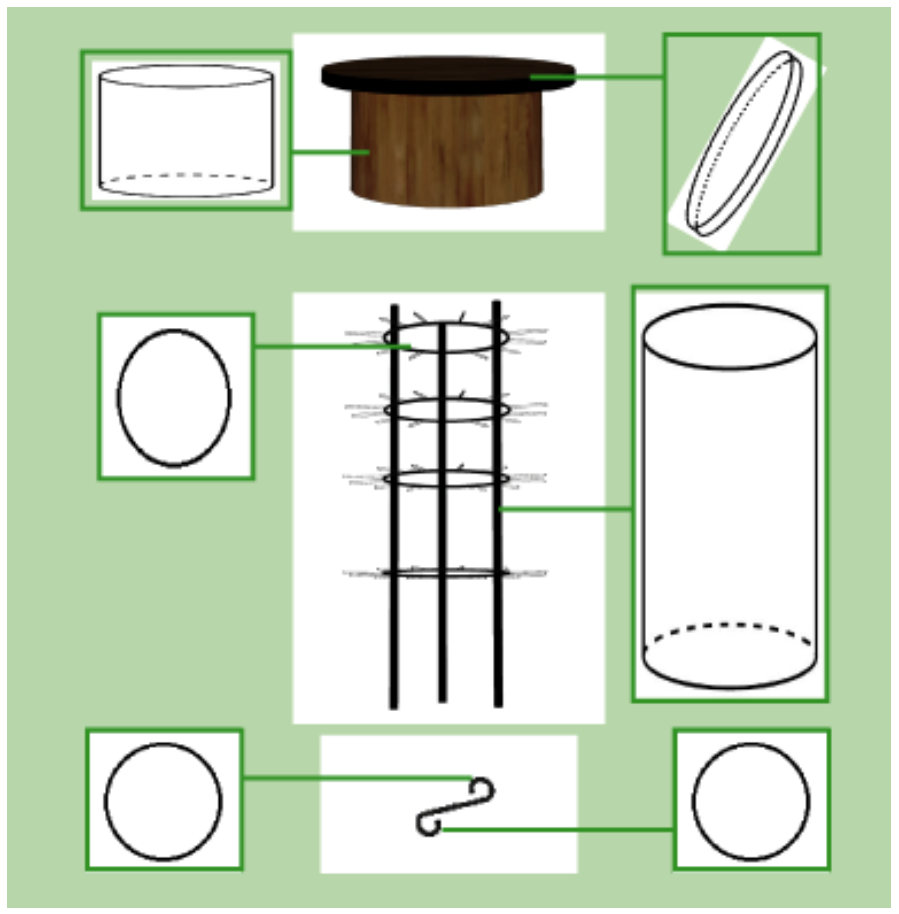

Fonte: o autor

Para a Análise da Tarefa, foi realizada uma visita de campo em alguns supermercados da cidade de Maceió - AL, onde os autores puderam fotografar e analisar a realização da tarefa. De acordo com as observações feitas nos estabelecimentos, foram identificadas duas situações principais sobre a tarefa a ser realizada. Na primeira, a utilização da fruteira por pessoas sem necessidades especiais e na segunda, a utilização de fruteiras por pessoas com necessidades especiais. Em ambas as situações, a fruteira pode ser de fácil acesso ou não, devido a vários fatores como dimensionamento inadequado e ambiente apertado. Visto isso, a tarefa foi dividida em cinco micro-tarefas sequenciais, como:

\section{Posicionar-se;}

2. Avançar o braço verticalmente/horizontalmente;

3. Segurar a sacola com uma das mãos

4. Pegar a fruta - pega de precisão ou de força;

5. Analisar se a fruta está boa - manejo grosseiro.

Contatou-se que algumas das tarefas estão sendo realizadas de maneira inadequada. Além dos vícios de postura que os usuários já adquiriram ao longo de sua vida, há fatores externos que contribuem para a adoção de posturas incorretas. Para os usuários que desempenham essa tarefa em pé, os problemas são relacionados, em grande parte, às fruteiras que não distribuem as frutas em alturas variadas, fazendo com que o usuário seja obrigado a se curvar ou se esticar para alcançar e escolher as frutas. Isso pode causar danos à coluna e outras partes do corpo (figura 6). 
Figura 6 - Realização da tarefa por pessoas sem necessidades especiais

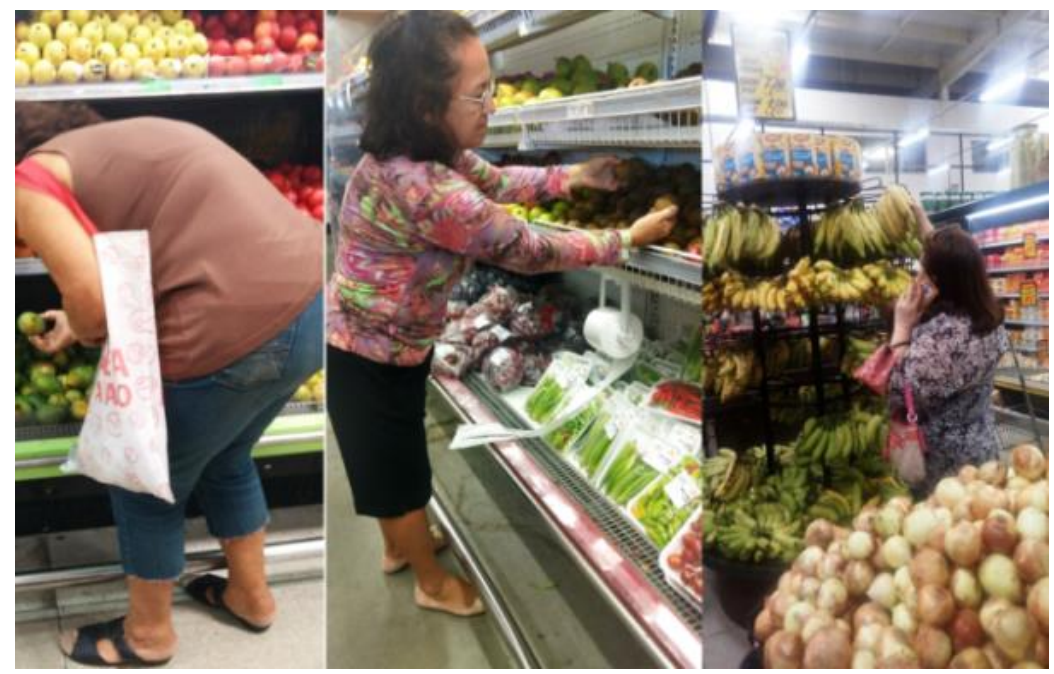

Fonte: o autor

A dificuldade é ainda maior para os usuários que desempenham a tarefa de escolher frutas na posição sentada (cadeirantes). As dificuldades acontecem pelo mau dimensionamento das fruteiras, logo que o espaço no qual o produto está inserido não possibilita o giro da cadeira de rodas.

Figura 7 - Realização da tarefa por pessoas com necessidades especiais

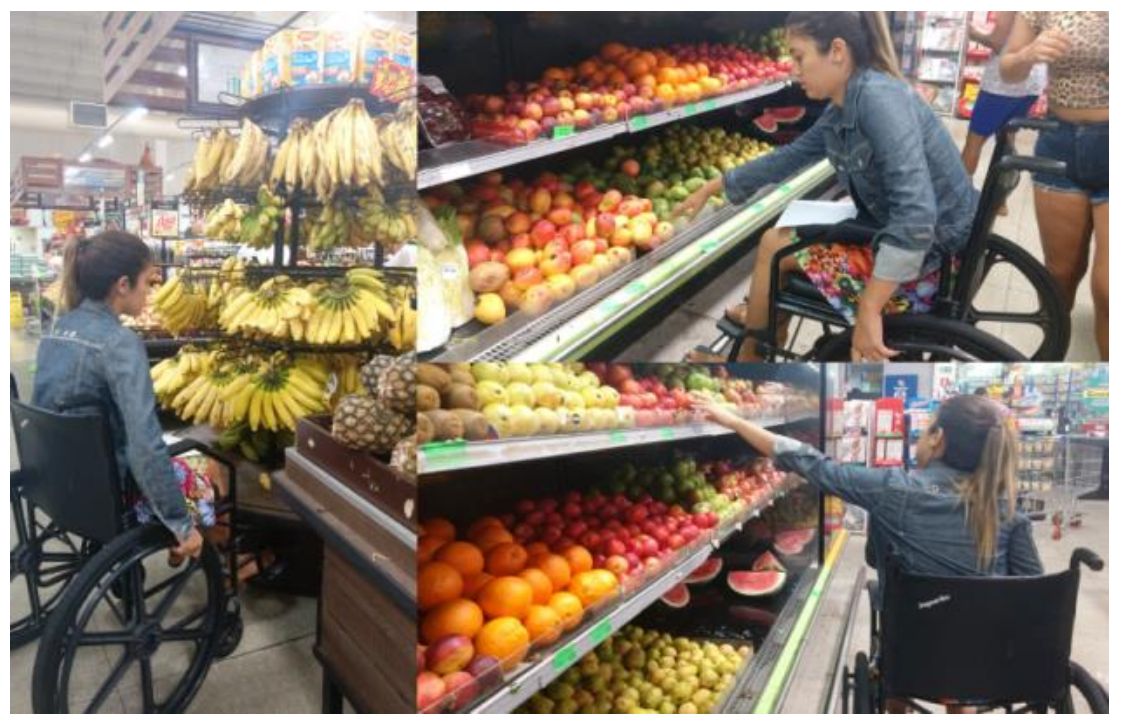

Fonte: o autor

Com base em Panero e Zelnik (2011), uma cadeira de rodas tem uma altura de $92,5 \mathrm{~cm}$, os braços ficam a $72,5 \mathrm{~cm}$ do chão e a altura dos olhos fica a aproximadamente $117,6 \mathrm{~cm}$. As dimensões das fruteiras similares não são compatíveis a esses valores. Sendo assim, um cadeirante tem dificuldade em acessar as frutas devido às alturas incorretas e da própria estrutura 
das fruteiras, que impedem a aproximação frontal. $\mathrm{O}$ acesso é permitindo apenas lateralmente, o que pode prejudicar a coluna desse usuário.

Figura 8 - Medidas da cadeira de rodas

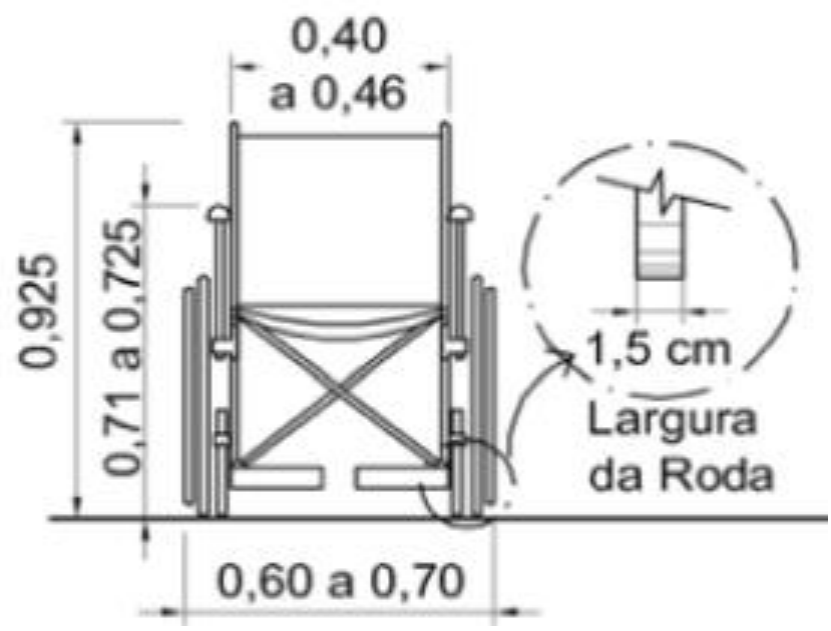

Fonte: Adaptado de Panero e Zelnik (2011)

Tendo em vista as diferenças corporais dos vários usuários em potencial. Levou-se em consideração no estudo antropométrico, os percentis mínimos para homens, mulheres, homens idosos, mulheres idosas e cadeirantes. Na tabela 1 são listados os percentis a serem trabalhados. Após análise ergonômica foi possível estabelecer as dimensões que o novo projeto deverá possuir, conforme na figura 9.

Tabela 1 - Percentis do Público-Alvo

\begin{tabular}{|c|c|c|c|c|c|}
\hline & HOMENS & MULHERES & $\begin{array}{l}\text { HOMENS } \\
\text { IDOSOS }\end{array}$ & $\begin{array}{l}\text { MULHERES } \\
\text { IDOSAS }\end{array}$ & CADEIRANTES \\
\hline Altura média & 1,63 & 1,61 & 1,55 & 1,40 & 1,30 \\
\hline $\begin{array}{l}\text { Máximo alcance frontal } \\
\text { de apreensão }\end{array}$ & 0,80 & 0,67 & 0,76 & 0,64 & 0,66 \\
\hline $\begin{array}{l}\text { Máximo alcance vertical } \\
\text { de apreensão }\end{array}$ & 2,10 & 1,99 & 2,00 & 1,82 & 1,40 \\
\hline
\end{tabular}

Fonte: adaptado de Panero e Zelnik (2011) 
Após análise ergonômica foi possível estabelecer as dimensões que o novo projeto deverá possuir, conforme na figura 9.

Figura 9 - Demonstração de dimensões ideais

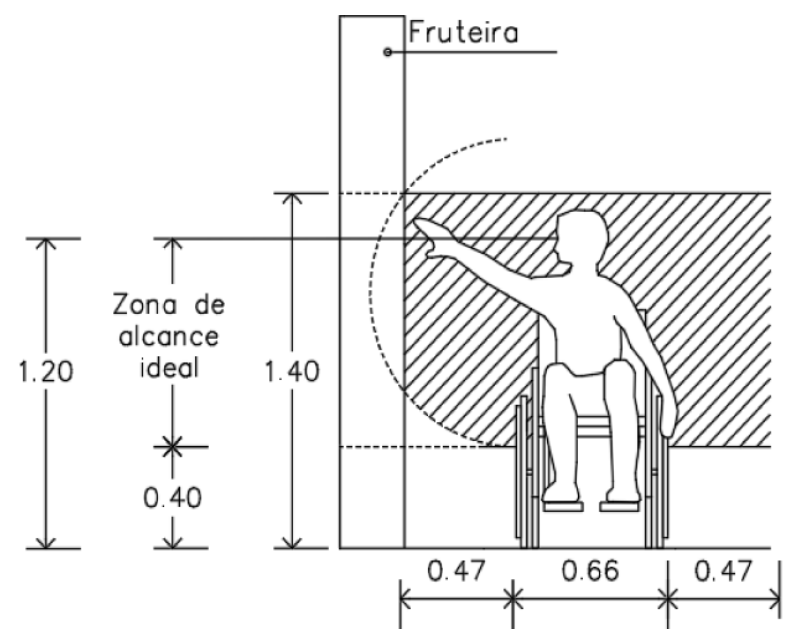

Fonte: o autor

\subsection{Definição do problema e dos objetos}

Após o levantamento de dados verificou-se que não existe uma fruteira que atenda de maneira satisfatória o público alvo, mas existem alguns produtos que atendem parcialmente e possuem características que podem contribuir para o desenvolvimento de um produto mais completo.

A etapa de requisitos e parâmetros tem por objetivo sintetizar informações coletadas durante as análises anteriores. Os requisitos referem-se à condição exigida para a realização do projeto. Os parâmetros são os meios que serão utilizados para a execução do produto. No quadro são listados os requisitos e parâmetros do projeto.

Quadro 2 - Requisito e Parâmetros.

Uso

- Deverá ser tolerante ao erro, mantendo isolados ou excluindo elementos perigosos.

- Deverá ter manuseio confortável por todo o público alvo (mulheres, homens, cadeirantes, idosos, deficientes visuais), através de um sistema que possibilite o uso sem muito esforço.

Ergonomia

- Deverá evitar mudanças frequentes de postura, por meio de um sistema manual ou mecânico que elimine essa necessidade. 
- Deverá possuir alcance baseado no percentil mínimo (5\%), com medidas entre $60 \mathrm{~cm}$ e $120 \mathrm{~cm}$ de altura.

- Deverá possibilitar a movimentação de cadeirantes, possuindo recuo de $47 \mathrm{~cm}$ de profundidade e $40 \mathrm{~cm}$ de altura.

- Deverá conter informações acessíveis às pessoas com baixa visibilidade e deficientes visuais, utilizando diferentes meios de comunicação e cores que facilitem a visualização.

Estético

- Deverá transmitir a ideia de movimento e dinâmica, possuindo formas arredondadas.

Fonte: o autor

\section{Conclusão}

Com base nos estudos e análises deu-se início a geração de conceitos e alternativas para um produto mais satisfatório e eficiente. Os requisitos e parâmetros serviram como referência para o estabelecimento de prioridades, onde foi definido que a ergonomia é mais importante que a estética, por exemplo. Serviu também como guia na concepção de um sistema funcional, a fim de estabelecer o modo como o produto será utilizado.

Sendo assim, gerou-se uma alternativa que tem como principal diferencial o fato de sua estrutura ser suspensa. A fruteira projetada é formada por duas fileiras de caixas dispostas lado a lado, e seu sistema funcional não interliga todas as caixas, ou seja, o usuário não move todo o sistema ao mover uma caixa. As caixas são presas na estrutura por uma alavanca que permite que o usuário puxe e aproxime as caixas que estão dispostas em altura elevada, até sua altura.

Figura 10 - Alternativa Gerada

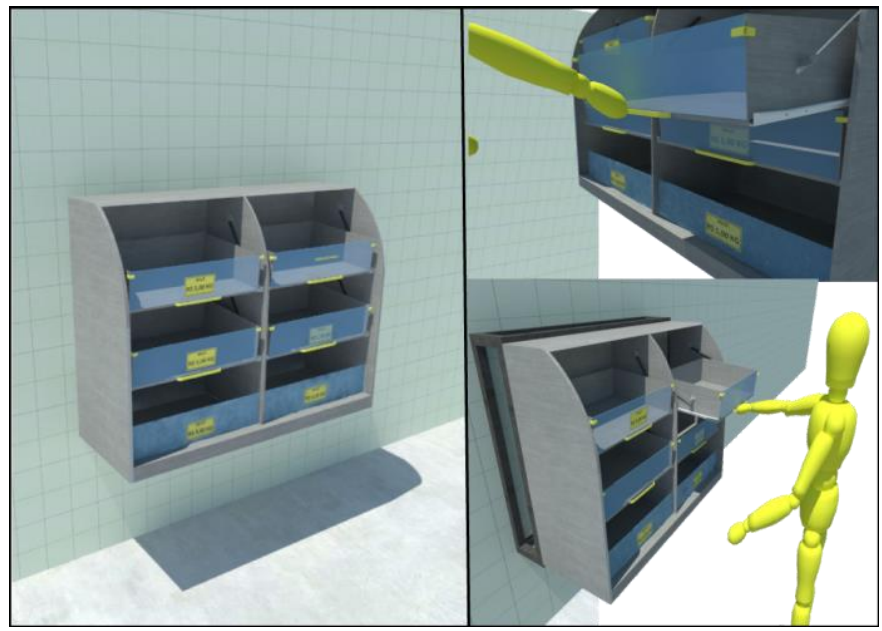

Fonte: o autor 
A alternativa apresentada foi considerada a ideal por possuir diversas características condizentes com os princípios do Design Universal. A primeira característica é o fato de possuir sistema funcional favorável que, além de possibilitar o manuseio confortável, ajuda na extinção de mudanças frequentes de postura. Além disso, a nova fruteira é tolerante ao erro, pois possui sistema totalmente manual, evitando acidentes com eletricidade.

A tarefa poderá ser realizada na parte frontal da fruteira, logo, permite a movimentação de cadeirantes. O fato de poder se manusear as prateleiras até o alcance do usuário, evitando mudanças constantes de postura, também se apresenta como positivo. Os requisitos funcionais e estéticos também foram atendidos com a inserção de um sistema adequado à visualização de informações e valores. A inserção de forma arredondada na lateral do objeto também evita acidentes.

O objetivo primordial deste estudo foi desenvolver uma fruteira, com base nos princípios do Design Universal. Para isso, prezou-se pela ergonomia, de modo que os usuários tivessem o mínimo de mudança da postura em sua utilização. O problema identificado atinge muitos frequentadores de supermercados, como idosos e pessoas portadores de necessidades especiais. O produto desenvolvido reduziu o tempo de realização da tarefa, o esforço do usuário em $80 \%$ e otimizou o espaço em volta da fruteira, com a tarefa podendo ser realizada por cadeirantes.

É um produto de grande utilidade, desenvolvido com sistema manual, fácil de ser implementado e com estética semelhante às fruteiras já existentes no mercado. Com o uso das ferramentas e métodos de Lobach, somados a ferramentas e estudos considerados pertinentes foi possível investigar o problema de forma coerente, gerar soluções para o mesmo e desenvolver uma ideia levando em consideração todos os fatores necessários para um produto (forma, estrutura, cores, materiais, funcionamento, dimensionamento).

\section{Referências}

ADUL, J.; WEERDMEESTER, B. Ergonomia prática. São Paulo: Edgar Blücher, 2004.

BAXTER, M. Projeto de produto. São Paulo: Edgard Blücher, 1998.

BONSIEPE, Gui et. al. Metodologia experimental: desenho industrial. Brasília: CNPq/Coordenação editorial, 1984.

BROWN, Tim. Design Thinking: uma metodologia poderosa para decretar o fim das velhas ideias. Rio de Janeiro. Elsevier, 2008.

BUZAN, Tony. Mapas mentais e sua elaboração. São Paulo: Editora Cultrix. 2005.

CARLETTO et. al. Desenho Universal: um conceito para todos. São Paulo, 2008.

CYBIS. W.; HOLTZ. A.; FAUST. R. Ergonomia e usabilidade: conhecimentos, métodose aplicações. São Paulo: Novatec editora, 2010.

ELIAS, Norbert. Sobre o tempo. Rio de Janeiro: Jorge Zahar, 1984.

GOMES FILHO, J. Ergonomia do objeto: sistema técnico de leitura ergonômica. São Paulo: Escrituras Editora, 2010.

GOMES FILHO, João. Ergonomia do Objeto: Sistemas de Leitura Ergonômica. São Paulo:Escrituras 
editora, 2003.

GUTIERREZ, A.S.D. Danos mecânicos pós-colheita em pêssego fresco. 124f. Tese (Doutorado em Produção Vegetal), Escola Superior de Agricultura "Luiz de Queiroz", Universidade de São Paulo. Piracicaba, 2005.

IBGE - Instituto Brasileiro de Geografia e estatística. Dados sobre População do Brasil, PNAD (Pesquisa Nacional por Amostra de Domicílios), 2002. [online] Disponível em: https://ww2.ibge.gov.br/home/presidencia/noticias/25072002pidoso.shtm. Arquivo consultado em 01 de abril de 2018.

IBGE - Instituto Brasileiro de Geografia e estatística. PNS - Pesquisa Pesquisa Nacional de Saúde, 2015. [online] Disponível na internet via WWW URL: https://ww2.ibge.gov.br/home/presidencia/noticias/08052002tabulacao.shtm. Arquivo consultado em 01 de abril de 2018.

IIDA, I. Ergonomia: projeto e produção. São Paulo: Edgar Blücher; 2005.

KARWOWSKI, W.; SOARES, M.; STANTON, N. Handbook of Human Factors in Consumer Product Design. Boca Raton, CRC Press, 2011.

KOTLER, P.; KELLER, K. L. Administração de Marketing . São Paulo, 2006.

LIMA, F. J. de.; SILVA, F. T. dos S. Barreiras atitudinais: obstáculos à pessoa com deficiência na escola. In: (org.) SOUZA, O. S. H. Itinerários da Inclusão Escolar: múltiplos olhares, saberes e práticas. Porto Alegre: AGE, 2007.

LÖBACH, B. Design Industrial: Bases para a configuração dos produtos industriais. São Paulo: Edgard Blucher, 2001.

MORAES, A. Ergodesign do ambiente construído e habitado. Rio de Janeiro: IUSER. 2004

MUNARI, Bruno. Das coisas nascem coisas. São Paulo: Martins Fontes, 2002.

PANERO, Julius. ZELNIK, Martin. DI MARCO, Anita Regina. Dimensionamento humano para espaços interiores: um livro de consulta e referência para projetos.Barcelona: G. Gili, 2011.

VIDAL, M. C. Guia para Analise Ergonômica do Trabalho (AET) na Empresa. EVC: Rio de Janeiro. 2008.

WISNER, A. Por dentro do trabalho: ergonomia método e técnica. São Paulo: FTD/ Oboré, 1987 Inclusão - Construindo uma sociedade para todos. Coleção

Inclusão. Rio de Janeiro: WVA, 1997. 